\title{
MODEL MATEMATIS PREDIKSI KESUKSESAN PRODUK MEMPERTIMBANGKAN BUDAYA PADA KENDARAAN BERMOTOR RODA EMPAT
}

\author{
Ratih Setyaningrum \\ Program Studi Teknik Industri Fakultas Teknik \\ Universitas Dian Nuswantoro Semarang \\ Email: ratihha@gmail.com \\ Subgyo dan Andi Rahadiyan Wijaya \\ Jurusan Teknik mesin dan Industri Fakultas Teknik \\ Universitas Gadjah Mada
}

\begin{abstract}
Cultural aspects and Maslow needs has been considered on product development process. There has indication of product selection mutation based on Maslow needs ability. Based on these conditions, formulation of successful product development strategy in the future need to consider cultural aspects. Therefore, the purpose of this study is to determine mathematical model of products four-wheeled vehicles and to predict success. Stages of research with KANO methods include developing mathematical models, the validation process models and best model selection. The results of a mathematical model based on market share indicates that the component mustbe inversely proportional to the success of the product, while the components of one-dimentional and attractive is directly proportional to the success of the product. Cultural aspects devided into 3 KANO categories, that is masculinity include into must-be and uncertainty avoidance included into one-dimentional. While power distance index, individualism and long term-orientation included into attractive.
\end{abstract}

Keyword: Cultural aspects; Marketshare; Mathematics model.

\begin{abstract}
ABSTRAK
Aspek budaya dan hirarki kebutuhan Maslow dipertimbangkan pada proses pengembangan produk. Terdapat indikasi adanya pergeseran pemilihan produk mobil yang didasarkan pada kemampuan pemenuhan kebutuhan Maslow. Sehingga pengembangan produk sukses untuk masa yang akan datang perlu mempertimbangkan aspek budaya. Oleh sebab itu, tujuan penelitian ini adalah menentukan model matematis prediksi kesuksesan produk yang mempertimbangkan budaya pada produk kendaraan roda empat. Tahapan penelitian dilakukan dengan metode KANO yang terdiri dari membangun model matematis, proses validasi model dan pemilihan model terbaik. Hasil model matematis kesuksesan produk berdasarkan market share menunjukkan bahwa komponen must-be berbanding terbalik dengan kesuksesan produk sedangkan komponen one-dimentional dan attractive berbanding lurus dengan kesuksesan produk. Aspek budaya terbagi pada 3 kelompok KANO yakni masculinity termasuk pada kelompok must-be, uncertainty avoidance termasuk pada kelompok one-dimentional sedangkan power distance index, individualism dan long term-orientation termasuk pada kelompok attractive.
\end{abstract}

Kata Kunci: Aspek budaya; Market share; Model matematis. 


\section{PENGANTAR}

Produk otomotif (mobil) yang mempertimbangkan budaya mulai diminati masyarakat Indonesia. Faktor budaya yang dipertimbangkan yaitu organisasi sosial (sistem kekerabatan) dan profesi pengguna (mata pencaharian). Produk mobil yang mempertimbangkan sistem kekerabatan masyarakat Indonesia antara lain mobil MPV (Multiple Purpose Vehicle) yang mampu meraih penjualan sebesar $79 \%$. Produk mobil yang dirancang dengan mempertimbangkan profesi pengguna antara lain motor bak terbuka beroda tiga dan becak motor (bentor). Penjualan motor bak terbuka beroda tiga bermerek Viar meningkat 30\% (bisnisjateng, 2013). Demikian juga dengan produk bentor (becak motor) yang menjadi simbol budaya Gorontalo. Hal tersebut membuktikan bahwa produk otomotif yang mempertimbangkan budaya berkembang dan diminati masyarakat Indonesia.

Selain pendekatan budaya, hirarki kebutuhan Maslow telah digunakan sebagai acuan pengembangan produk. Berdasarkan hirarki Maslow, perusahaan telah mengembangan dan mengklasifikasikan produknya menjadi beberapa kelas yaitu low product, medium product, high product, dan luxury product. Perusahaan Toyota mengklasifikasikan produk mobil menjadi beberapa jenis antara lain MPV (Multiple Vehicle Purpose), SUV (Sport Utility Vehicle) dan mobil compact. Klasifikasi produk mobil Toyota MPV menurut otomotif (2014) terdiri dari Avansa (low), Innova (medium), dan NAV1 (high). Klasifikasi produk mobil Toyota SUV menurut otomotif (2013) terdiri dari Rush (low), Fortuner (medium), dan Hilux (High). Produk mobil Toyota jenis compact menurut Lutfi (2013) antara lain Agya (LGCC), Etios (compact), dan Yaris (premium compact). Proses klasifikasi produk tersebut menggunakan pendekatan hirarki kebutuhan Maslow.

Terdapat indikasi adanya pergeseran pemilihan produk mobil berdasarkan kemampuan pemenuhan kebutuhan Maslow konsumen. Saat ini, masyarakat Indonesia cenderung memilih produk kelas low produk.
Hal tersebut ditunjukkan pada pemilihan produk mobil jenis MPV, SUV, dan compact. Pada gambar satu menunjukkan data penjualan produk MPV, SUV, dan mobil jenis compact pada kelas low, medium, dan high (Toyota, 2013). Berdasarkan gambar satu diperoleh urutan penjualan produk MPV, SUV dan compact dari yang tertinggi ke terendah yaitu low product, medium product, dan high product. Penjualan tertinggi pada kelas low product yaitu Toyota MPV model Avansa, Toyota SUV model Rush, dan Toyota compact model Agya. Adanya peningkatan daya beli masyarakat, mengakibatkan terjadinya pergeseran pemilihan produk dari low product menuju kelas di atasnya. Hal tersebut ditunjukkan oleh perbandingan penjualan mobil berbagai kelas di Indonesia, Eropa, dan Jepang yang disajikan pada gambar dua. Di Indonesia, penjualan mobil Toyota Avansa (Avensis) dan Toyota Camry relatif lebih tinggi daripada Eropa dan Jepang. Konsumsi masyarakat Indonesia masih didominasi kelas low product, tetapi kedepan akan terjadi pergeseran pemenuhan menuju kelas medium product. Hal tersebut terlihat pada penjualan model Toyota yang terletak pada kelas medium product (Camry) dengan harga dan kualitas yang relatif tinggi. Hasil tersebut menunjukkan adanya peluang pergeseran pemilihan produk menuju kelas yang lebih tinggi. Oleh karena itu, hirarki kebutuhan Maslow perlu dipertimbangkan dalam proses pengembangan produk.

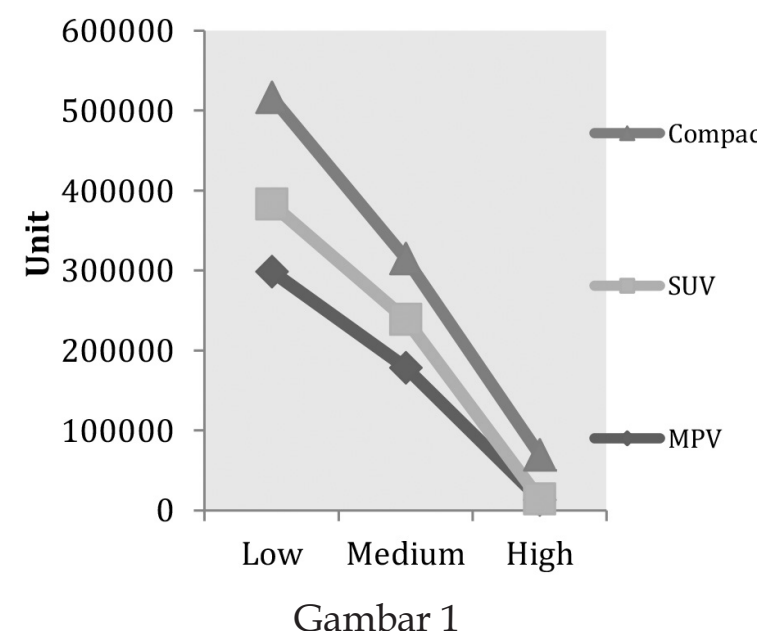

Penjualan mobil Toyota Jenis Compact, MPV, dan SUV (Toyota, 2013) 


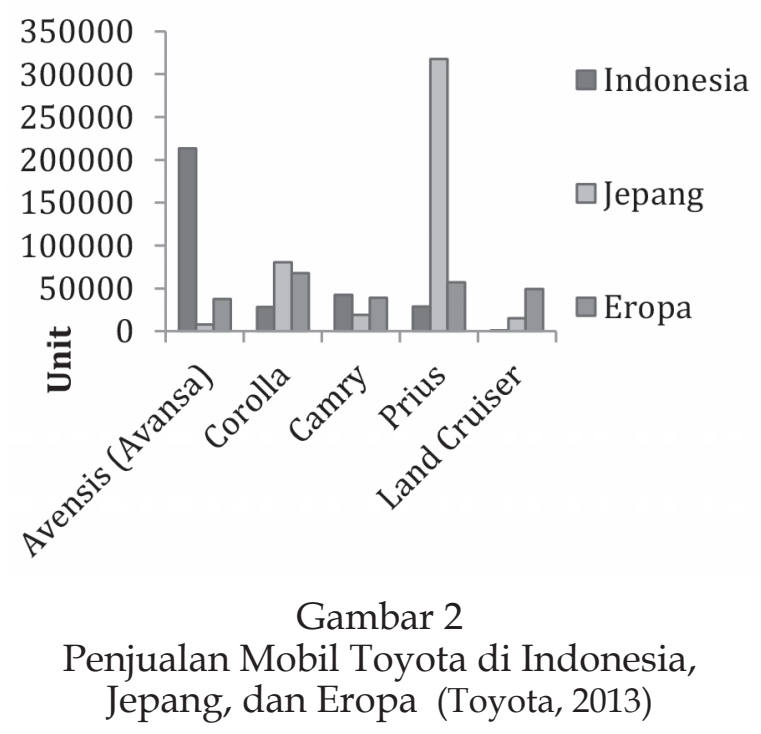

Berdasarkan hal tersebut, aspek budaya, hirarki kebutuhan Maslow, dan daya beli masyarakat, diperkirakan akan mempengaruhi keputusan pembelian produk kendaraan roda empat. Perlu dirumuskan strategi pengembangan produk sukses untuk masa yang akan datang dengan mempertimbangkan aspek-aspek tersebut. Oleh karena itu, diperlukan suatu model prediksi kesuksesan produk yang mempertimbangkan budaya untuk produk kendaraan roda empat sehingga tujuan penelitian ini sebagai berikut: pertama, Menentukan model matematis prediksi kesuksesan produk berbasis budaya pada produk kendaraan roda empat. Kedua, Menguji keberhasilan model matematis prediksi kesuksesan produk berbasis budaya.

KANO merupakan metode penelitian yang digunakan untuk mengklasifikasikan atribut yang terdapat dalam suatu produk berdasarkan cara atribut ini dalam mempengaruhi konsumen dan efeknya terhadap kepuasan konsumen. Kepuasan konsumen didefinisikan dalam istilah one-dimensional yang berarti bahwa peningkatan pemenuhan customer requirement akan mengakibatkan peningkatan terhadap kepuasan konsumen. Pada tahun 1980, Dr. Noriaki kano mengembangkan suatu metode yang menolak hipotesis awal mengenai kepuasan konsumen tersebut (Yang, 2005). Metode ini kemudian disebut dengan model kano.

Pada model kano, kepuasan konsumen didefinisikan menjadi lima komponen utama yaitu must-be, one-dimensional, attractive, indifferent, dan reverse. Bagian model kano disajikan pada gambar tiga.

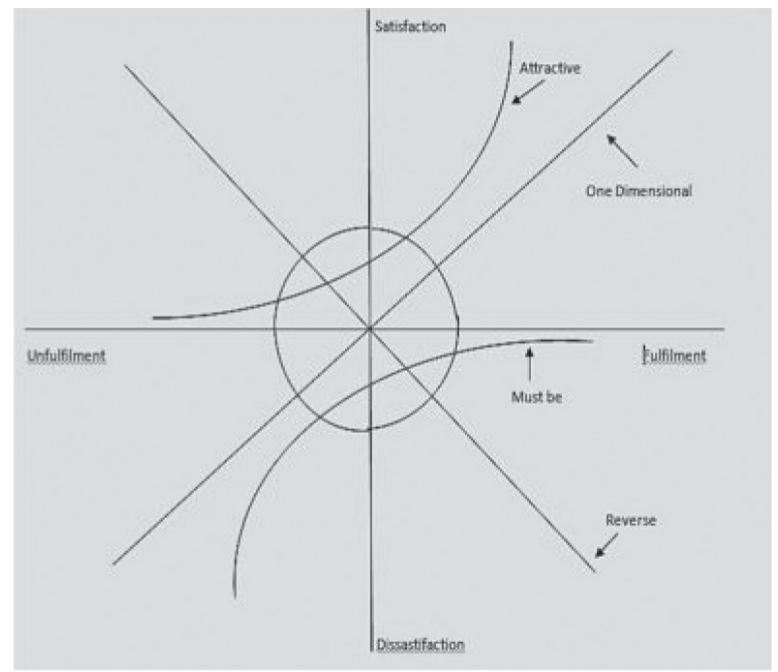

Gambar 3

Bagan Model Kano

(Yang, 2005)

Kelompok utama kategori must-be atau basic requirement merupakan variabel yang harus dipenuhi oleh suatu produk. Konsumen akan melakukan penolakan terhadap produk apabila atribut ini tidak dipenuhi, namun tidak akan memberikan nilai tambah apabila variabel tersebut terpenuhi. Febrita (2011) melakukan pendekatan logaritmik untuk menggambarkan persamaan yang dibentuk oleh kurva kategori must-be. Persamaan kategori must-be dapat dilihat pada persamaan (1).

$Y_{1}=A(\ln X)+B$

Kelompok kategori one-dimensional atau performance requirements merupakan komponen kesuksesan produk yang memiliki pola linear terhadap kepuasan konsumen. Kepuasan akan meningkat jika atribut yang ada dalam kategori ini dipenuhi, tetapi akan menurun ketika atribut ini tidak terpenuhi. Persamaan kelompok kategori one-dimensional dapat dilihat di persamaan (2). 


$$
\mathrm{Y}_{2}=\mathrm{CX}+\mathrm{D}
$$

Kelompok kategori attractive atau delighter requirement merupakan variabel yang dianggap sebagai sisi pembeda atau dari suatu produk dibandingkan produk lain. Lieberman (2008) menyatakan bahwa attractive requirement merupakan keunikan produk yang sulit ditiru oleh kompetitor. Tingkat kepuasan konsumen akan meningkat cukup pesat dengan adanya atribut pada kategori ini, tetapi jika atribut kategori ini tidak ada tidak akan menyebabkan penurunan terhadap tingkat kepuasan konsumen. Febrita (2011) menggunakan pendekatan terhadap pola eksponensial untuk menggambarkan persamaan kategori ini. Persamaan untuk kategori attractive dapat dilihat dilihat pada persamaan (3).

$\mathrm{Y}_{3}=\mathrm{E}\left(\mathrm{e}^{\mathrm{fx}}\right)$

Selain ketiga kelompok kategori di atas masih terdapat atribut reverse dan indifferent, atribut reverse merupakan atribut yang tidak diharapkan dalam sebuah produk (Wijaya, 2011). Kategori reverse merupakan komponen yang apabila atributnya terpenuhi akan mengakibatkan ketidakpuasan konsumen. Persamaan kategori reverse menggunakan pendekatan hubungan linear dengan koefisien negatif.

Penelitian metode KANO yang menggunakan variabel budaya telah dilakukan oleh Bennur \& Jin (2012) pada produk pakaian berbasis cross-culture untuk US dan Indian. Produk otomotif kendaraan roda dua dan roda empat telah diteliti oleh Prasetyo (2013) menggunakan model KANO. Produk otomotif mobil juga telah diteliti oleh Sosatrio (2014), tetapi pada penelitian tersebut belum mempertimbangkan aspek budaya masyarakat.

\section{Metode}

Objek penelitian yaitu produk kendaraan roda empat. Produk tersebut terbagi menjadi tiga kelas yaitu: pertama, LCGC yang terdiri dari merek Daihatsu tipe Ayla, merek Honda tipe Brio Satya, merek Suzuki tipe Wagon R, dan merek Toyota tipe Agya. Kedua, Compact yang terdiri dari merek Honda tipe Brio, merek
KIA tipe Picanto, merek Mitshubishi tipe Mirage, merek Suzuki tipe Splash, dan Merek Toyota tipe Etios. Ketiga, Premium Compact yang terdiri dari merek Daihatsu tipe Sirion, merek Honda tipe Jazz, merek Hyunday tipe G.Avega, merek KIA tipe Rio, merek Mazda tipe Demio, merek Nissan tipe March, merek Suzuki tipe SX4, merek Toyota tipe Yaris, Merek For tipe Fiesta, merek Chevrolet tipe Aveo, dan merek Volkswagen tipe Golf.

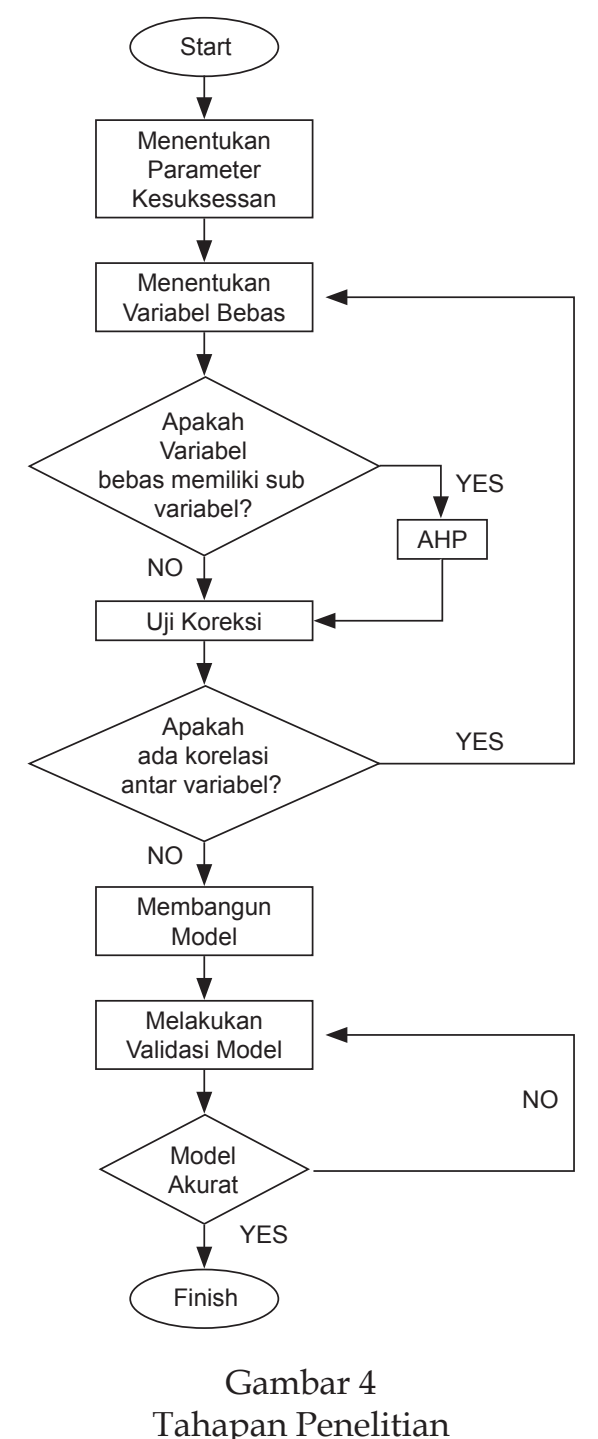

Tahapan penelitian dapat dikelompokkan menjadi tiga aktivitas utama sebagai berikut: Pertama, Membangun Model Matematis merupakan Data yang telah terkumpul, dikelompokkan dengan menggunakan tiga kebutuhan utama yang terdapat 
dalam model Kano yaitu must-be requirement, one-dimensional requirement, dan attracttive requirement. Model matematis dibangun dengan menggunakan $80 \%$ data pembangun model. Model matematis yang dibangun akan dinilai melalui nilai koefisien determinasi $\left(\mathrm{R}^{2}\right)$ untuk menilai seberapa tinggi sebuah model matematis mampu merepresentasikan data model pembangun.

Kedua, Validasi Model Matematis merupakan Model matematis yang telah dibangun diuji dengan menggunakan 20\% dari data keseluruhan yang berperan sebagai data validasi. Pada tahap ini data validasi menjadi nilai input pada model untuk melihat tingkat kemampuan model dalam memberikan prediksi peringkat kesuksesan produk. Hasil prediksi peringkat kemudian dibandingkan dengan peringkat aktual. Nilai mutlak selisih masing-masing peringkat dalam satu jenis industri kemudian dibandingkan dengan kombinasi kesalahan peringkat total.

Ketiga, Pemilihan Model Terbaik. Pemilihan model terbaik dipilih dengan menggunakan dua kriteria yaitu adalah dengan memperhatikan nilai $\left(\mathrm{R}^{2}\right)$ model dan kemampuan prediksi model. Model terbaik adalah model yang memiliki koefisien determinasi dan kemampuan prediksi yang tinggi.

\section{HASIL DAN PEMBAHASAN}

Variabel dependen penelitian ini adalah kesuksesan produk. Pada analisis awal ini diperoleh dari market share produk mobil. Sedangkan variabel independen meliputi performance (X1), durability (X2), after sales (X3), maintenance \& repair $(\mathrm{X} 4)$, price $(\mathrm{X} 5)$, brand $(\mathrm{X} 6)$, power distance index (X7), individualism (X8), masculinity (X9), uncertainty avoidance (X10), dan long term orientation (X11). Aspek budaya ditunjukkan pada variabel $\mathrm{X} 7$ hingga X11. Data sekunder digunakan pada penelitian awal ini, dengan menggunakan penelitian Sosatrio (2014) untuk menentukan data variabel dependen dan independen.

Pengelompokan variabel value preposition produk mobil dilakukan berdasarkan pendekatan kurva model kano dan perhitungan nilai sum of square error (SSE). Tabel satu menunjukkan hasil SSE untuk setiap variabel. Tahap berikutnya memilih nilai SSE terkecil yang digunakan untuk mengelompokkan varibel ke dalam tiga komponen KANO. Tabel kedua menyajikan hasil pengelompokan variabel ke dalam komponen model KANO.

Pembangunan model matematis dilakukan berdasarkan pengelompokan variabel ke dalam komponen model KANO. Pembangunan model perlu mempertimbangkan karakteristik dari hubungan antarvariabel yang berkorelasi kuat yaitu di atas 0.51 . Tahap berikutnya adalah membangun beberapa alternatif model seperti yang disajikan pada tabel tiga. Penelitian awal ini menghasilkan empat alternatif model.

Tabel 1

Hasil Perhitungan SSE untuk Setiap Variabel

\begin{tabular}{lccc}
\hline Variabel value preposition & $\begin{array}{c}\text { Must-be } \\
\text { (logaritmik) }\end{array}$ & $\begin{array}{c}\text { One-dimentional } \\
\text { (linier) }\end{array}$ & $\begin{array}{c}\text { Attractive } \\
\text { (eksponensial) }\end{array}$ \\
\hline Performance (X1) & 2.354 & 2.442 & 2.303 \\
Durability (X2) & 2.539 & 2.503 & 2.523 \\
After sales (X3) & 2.140 & 2.113 & 2.073 \\
Maintenance \& repair (X4) & 2.068 & 1.963 & 1.876 \\
Price (X5) & 2.398 & 2.404 & 2.433 \\
Brand (X6) & 2.461 & 2.574 & 2.581 \\
Power distance index (X7) & 1.934 & 1.796 & 1.681 \\
Individualism (X8) & 2.600 & 2.599 & 2.599 \\
Masculinity (X9) & 2.469 & 2.499 & 2.526 \\
Uncertainty avoidance (X10) & 2.576 & 2.434 & 2.475 \\
Long term-orientation (X11) & 2.589 & 2.574 & 2.575 \\
\hline
\end{tabular}


Tabel 2

Pengelompokan Variabel ke dalam Komponen Model KANO

\begin{tabular}{lll}
\hline \multicolumn{1}{c}{ Must-be (logaritmik) } & \multicolumn{1}{c}{ One-dimentional (linier) } & \multicolumn{1}{c}{ Attractive (eksponensial) } \\
\hline Price (X5) & Durability (X2) & Performance (X1) \\
Brand (X6) & Individualism (X8) & After Sales (X3) \\
Masculinity (X9) & Uncertainty Avoidance (X10) & MaintananceErepair (X4) \\
& Long term orientation (X11) & Power Distance Index (X7) \\
& & Individualism (X8) \\
& Long term orientation (X11) \\
\hline
\end{tabular}

Tabel 3

Alternatif Model yang Dihasilkan

\begin{tabular}{clll}
\hline Alternatif model & Must-be (logaritmik) & One-dimentional (linier) & \multicolumn{1}{c}{ Attractive (eksponensial) } \\
\hline Model 1 & $\mathrm{X} 1, \mathrm{X} 6, \mathrm{X} 9$ & $\mathrm{X} 2, \mathrm{X} 8, \mathrm{X} 10, \mathrm{X} 11$ & $\mathrm{X} 1, \mathrm{X} 3, \mathrm{X} 4, \mathrm{X} 7$ \\
Model 2 & $\mathrm{X} 1, \mathrm{X} 6, \mathrm{X} 9$ & $\mathrm{X} 2, \mathrm{X} 8, \mathrm{X} 10$ & $\mathrm{X} 1, \mathrm{X} 3, \mathrm{X} 4, \mathrm{X} 7, \mathrm{X} 11$ \\
Model 3 & $\mathrm{X} 1, \mathrm{X} 6, \mathrm{X} 9$ & $\mathrm{X} 2, \mathrm{X} 10, \mathrm{X} 11$ & $\mathrm{X} 1, \mathrm{X} 3, \mathrm{X} 4, \mathrm{X} 7, \mathrm{X} 8$ \\
Model 4 & $\mathrm{X} 1, \mathrm{X} 6, \mathrm{X} 9$ & $\mathrm{X} 2, \mathrm{X} 10$ & $\mathrm{X} 1, \mathrm{X} 3, \mathrm{X} 4, \mathrm{X} 7, \mathrm{X} 8, \mathrm{X} 11$ \\
\hline
\end{tabular}

Keempat alternatif model yang telah dibangun kemudian dipilih salah satu model terbaik. Pemilihan model terbaik dilakukan dengan membandingkan koefisien determinasi $\left(R^{2}\right)$ dari masing-masing alter- natif dan nilai kemampuan prediksi dari masing-masing alternatif ( $\mathrm{r}^{2}$ validasi). Hasil perhitungan nilai koefisien determinasi $\left(\mathrm{R}^{2}\right)$ dan kemampuan prediksi $\left(\mathrm{r}^{2}\right.$ validasi) disajikan pada Tabel 4.

Tabel 4

Alternatif Model yang Dihasilkan Pemilihan Produk

\begin{tabular}{|c|c|c|c|}
\hline Alternatif model & $\mathbf{R}^{2}$ model & $\mathbf{r}^{2}$ validasi & $\mathbf{r}^{2}$ \\
\hline Model 1 & $42.81 \%$ & $24.04 \%$ & $51.50 \%$ \\
\hline Model 2 & $46.06 \%$ & $21.60 \%$ & $54.50 \%$ \\
\hline Model 3 & $41,37 \%$ & $14.46 \%$ & $55.10 \%$ \\
\hline Model 4 & $43.23 \%$ & $15.99 \%$ & $55.60 \%$ \\
\hline
\end{tabular}

Tabel 4 menunjukkan bahwa alternatif model empat memiliki milai $\mathrm{R}^{2}$ tertinggi dan kemampuan prediksi ( $\mathrm{r}^{2}$ validasi) dan $\mathrm{r}^{2}$ relatif tinggi sehingga alternatif model empat merupakan model terpilih. Persamaan model terpilih ditunjukkan pada persamaan (4) hingga persamaan (7).

$\mathrm{Y} 1=0.218+0.07 \times 5+0.074 \times 6+0.348 \times 9$

$\mathrm{Y} 2=1.019-1.359 \times 2-0.181 \mathrm{X} 10$

$\mathrm{Y} 3=-0.96-0.12 \mathrm{X} 1+1.46 \mathrm{X} 3+0.45 \times 4+0.65 \mathrm{X} 7+0.1$

2X8-0.75X11

$\mathrm{Z} 4=-0.06 \mathrm{LN} Y 1-3.93+0.38 \mathrm{Y} 2-3.93+7.68 e^{0.11 Y 3} \ldots$
Berdasarkan persamaan matematis yang dihasilkan dari pengolahan KANO sebagai berikut: Pertama, Persamaan (4) menunjukkan bahwa ketiga variabel yang tergolong mustbe memiliki koefisien positif dan berbanding lurus dengan kesuksesan produk (market share) yakni price $(0,07)$, brand $(0,074)$ dan masculinity (0,348). Kedua, Persamaan (5) menunjukkan bahwa kedua variabel yang tergolong one dimensional berkorelasi negatif dan berbanding terbalik dengan kesuksesan produk (market share) yakni durability (01.359) dan uncertainty avoidance $(0,181)$. Ketiga, Persamaan (6) menunjukkan bahwa terdapat dua variabel yang tergolong attractive berkorelasi negatif dan berbanding terbalik dengan kesuksesan produk (market share) 
yakni performance $(0,21)$ dan long term-oriented $(0,75)$. Sedangkan empat variabel lainnya yang tergolong attractive berkorelasi positif dan berbanding lurus dengan kesuksesan produk (market share) yakni after sales $(1,46)$, maintenance $\mathcal{E}$ repair $(0,45)$, power distance index $(0,65)$ dan individualism $(0,12)$.

Keempat, Persamaan matematis kesuksesan produk pada persamaan (7) dirumuskan pada fungsi $Z$, menunjukkan bahwa komponen must-be memiliki nilai koefisien sebesar -0,06. Komponen onedimensional memiliki koefisien regresi linear sebesar 0,38. Koefisien attractive memiliki koefisien exponensial sebesar 0,11. Model ini memiliki konstanta -7,86. Kelima, Aspek budaya terbagi pada tiga kelompok KANO, yaitu masculinity termasuk pada kelompok must-be, uncertainty avoidance termasuk pada kelompok one-dimentional sedangkan power distance index, individualism, dan long term-orientation termasuk pada kelompok attractive.

\section{SIMPULAN}

Hasil model matematis kesuksesan produk berdasarkan market share menunjukkan bahwa komponen must-be berbanding terbalik dengan kesuksesan produk sedangkan komponen one-dimentional dan attractive berbanding lurus dengan kesuksesan produk.

Hasil perhitungan KANO menghasilkan persamaanmatematisyangmengelompokkan aspek-aspek budaya (X7 hingga X11) kedalam tiga (3) kategori kelompok KANO (must-be, one-dimentional, attractive). Kajian ini membutuhkan penelitian lanjutan yang mampu menentukan model kesuksesan produk dengan parameter kesuksesan selain market share. Diperlukan pula penelitian detail terkait variabel-variabel yang tergolong komponen must-be, one-dimentional dan attractive yang mampu menghasilkan model kesuksesan untuk berbagai produk.

\section{DAFTAR PUSTAKA}

Bennur, S., and Jin, B., 2013, Cross-cultural investigation of US and Indian customer apparel attributes choice applying KANO's theory, Journal of Fashion Marketing $\mathcal{E}$ Management, 17 (3), 306-321.

Bisnis Jateng, 2013, Penjualan Viar Jateng naik 30\%, http://www.bisnisjateng.com, [Online, accessed 10 Juni 2013].

Febrita,I., 2011, Model Peramalan Kesuksesan Produk Berbasis Pendekatan Kano, Tugas Akhir, Program Studi Teknik Industri, Universitas Gadjah Mada, Yogyakarta.

Lieberman, M.D., 2008, Design Performance the Kano Model, QUICK'S Marketing Research.

Otomotif, 2014, katergori SUV, http/ / www. oto.id.com/mobil-/kategori-suv, [online. Accessed 30 Maret 2015]

Prasetyo,W.,2013,PrediksiKesuksesanProduk Kendaraan Roda Dua dan Roda Empat dengan Framework Canvas Business, Tugas Akhir, Program Studi Teknik Industri, Universitas Gadjah Mada, Yogyakarta.

Sosatrio, R.B.F, 2014, Pengaruh Kualitas Terhadap Kesuksesan Produk Kendaraan Bermotor Roda Empat, Tugas Akhir, Program Studi Teknik Industri, Universitas Gadjah Mada, Yogyakarta.

Toyota Corporation, 2013, Toyota in The World.

Yang, C. C., 2005, The Refined Kano's Model and its Apllication, Total Quality Management, 16 (10), 1127-1137.

Wijaya, 2011, Pengembangan Model Prediksi Kesuksesan Produk, Tugas Akhir, Program Studi Teknik Industri, Universitas Gadjah Mada, Yogyakarta. 